\title{
Potential savings from increased substitution of generic for originator medicines in Europe
}

Received (in revised form): 28th June, 2006

\section{Steven Simoens}

is a professor at the Research Centre for Pharmaceutical Care and Pharmaco-economics. He is a health economist and leads the Centre's research into the economics of medicines, medical devices and related products. His research interests focus on issues surrounding competition and regulation of the pharmaceutical industry, and economic evaluation of medicines and medical devices. Previously, Steven worked at the Organisation for Economic Co-operation and Development and at the University of Aberdeen.

\section{Sandra De Coster}

graduated from the Katholieke Universiteit Leuven as a pharmacist. She spent two years in the pharmaceutical industry, where she participated in the regulatory affairs of herbal medicines. She then joined the Research Centre for Pharmaceutical Care and Pharmaco-economics as a research fellow. Her research interests focus on pharmacotherapy. In addition to this, she works part-time as a community pharmacist.

Abstract This study aims to estimate annual savings from increased generic substitution in the retail market of II European countries in 2004. Savings from generic substitution were calculated for the top ten active substances by public expenditure on originator medicines in each country. For each active substance, average price levels weighted by volume of sales of medicines belonging to the group of originator medicines and to the group of generic medicines were calculated. The price difference between originator and generic medicines was multiplied by the volume of originator medicines to be substituted. The analysis considered that, following generic substitution, 5 per cent of market volume for each active substance would be made up by originator medicines and 95 per cent by generic medicines. Increased generic substitution for the top ten active substances generated total potential savings of around $€ 3 \mathrm{bn}$, with country savings ranging from $€ \mathrm{IIm}$ in Poland to $€ \mathrm{Ibn}$ in Germany. Increased generic substitution would be expected to reduce public expenditure on originator medicines containing these active substances by at least 20 per cent in each country. Countries that pursue the development of their domestic generic medicines market, therefore, can expect to gain substantial savings from increased generic substitution.

Journal of Generic Medicines (2006) 4, 43-45. doi:10.1057/palgrave.jgm.4950040

Keywords: generic substitution, expenditure, medicines, international comparison

Steven Simoens

Research Centre for Pharmaceutical Care and Pharmaco-economics

Faculty of Pharmaceutical Sciences, K.U. Leuven

Onderwijs en Navorsing 2

P.O. Box 52I, Herestraat 49

3000 Leuven, Belgium

Tel: +32016323465

Fax: +32016323468

E-mail: steven.simoens@pharm.kuleuven.be

\section{INTRODUCTION}

The size of generic medicines retail markets varies widely between European countries. The proportion of the pharmaceutical retail market made up by generic medicines in volume (number of packs) exceeded 40 per cent in Denmark, Germany, Netherlands, Poland, United Kingdom, but did not surpass 20 per cent in Austria, Belgium, France, Italy, Portugal and Spain in 2004. ${ }^{1}$ This variation in 
the development of generic medicines markets suggests that not all countries are realising the full potential of generic medicines. The aim of this study is to quantify the potential savings from increased substitution of generic for originator medicines in Europe. This study was part of a wider project commissioned by the European Generic Medicines Association that analysed the European experience with developing generic medicine retail markets and proposed recommendations to further sustain generic medicines markets. ${ }^{2}$

\section{METHODOLOGY}

Focusing on the off-patent retail market, this exercise computed potential savings from substituting generic for originator medicines. The analysis was limited to the 10 active substances in each country that had the highest public expenditure of originator medicines in 2004. For each active substance in the top ten, average price levels weighted by volume of sales of the various medicines belonging to the group of originator medicines and to the group of generic medicines were calculated.

Annual savings were obtained by multiplying the price difference between generic and originator medicines by the volume of originator medicines to be substituted. In the United States, actual generic substitution rates have attained 80 per cent in specific medicine classes, ${ }^{3}$ and some analysts have set generic substitution target rates at 95 per cent. ${ }^{4}$ Our analysis considered that, following generic substitution, 5 per cent of market volume for each active substance would be made up by originator medicines and 95 per cent by generic medicines. Hence, this exercise calculated the potential savings from 'increased' rather than 'full' generic substitution.

\section{RESULTS}

Table 1 presents public expenditure on originator medicines for the top 10 of active substances in each country and savings from
Table I: Potential savings from increased generic substitution for the top 10 of active substances in selected countries, 2004

\begin{tabular}{lll}
\hline Country & $\begin{array}{l}\text { Public expendi- } \\
\text { ture on originator } \\
\text { medicines }\end{array}$ & $\begin{array}{l}\text { Savings from } \\
\text { generic substitution }\end{array}$ \\
\hline Germany & $€ 2,098,115,768$ & $€ 992,504,255(47 \%)$ \\
France & $€ I, 510,377,137$ & $€ 525,290,734(35 \%)$ \\
United Kingdom & $€ I, 070,786,874$ & $€ 349,844,935(33 \%)$ \\
Spain & $€ 9 \mid 6,910,433$ & $€ 301,740,171(33 \%)$ \\
Italy & $€ 844,954,289$ & $€ 263,508,563(31 \%)$ \\
Belgium & $€ 384,918,524$ & $€ I 60,784,134(42 \%)$ \\
Netherlands & $€ 360,226,124$ & $€ I 46,560,702(41 \%)$ \\
Portugal & $€ 280,649,104$ & $€ I 17,801,359(42 \%)$ \\
Denmark & $€ I 25,269,454$ & $€ 60,191,292(48 \%)$ \\
Austria & $€ 2 \mid 7,610,673$ & $€ 57,962,838(27 \%)$ \\
Poland & $€ 54,207,557$ & $€ I I, 178,228(21 \%)$ \\
Total & & $€ 2,987,367,211$ \\
\hline
\end{tabular}

Note: Savings from generic substitution are expressed in absolute terms and as a percentage of public expenditure on originator medicines.

increased generic substitution in absolute terms. Increased substitution of generic for originator medicines could yield considerable savings, amounting to an estimated total of around $€ 3$ bn for the 11 countries studied. The size of potential savings varies widely between countries, ranging from $€ 11 \mathrm{~m}$ in Poland to $€ 1$ bn in Germany.

Table 1 also indicates that public expenditure on originator medicines can be substantially reduced as a result of increased generic substitution. For the top ten active substances in 2004, generic substitution would be expected to reduce public expenditure on originator medicines containing these active substances by at least 20 per cent in selected countries. At one end of the spectrum, a potential proportional reduction of 21 per cent could be attained in Poland. At the other end, public expenditure on originator medicines could nearly be halved by means of increased generic substitution in Denmark and Germany.

\section{DISCUSSION}

Few studies have been published that calculate possible savings from increased generic substitution and these studies related to individual countries. ${ }^{3,5-7}$ This paper has 
highlighted the variation in potential savings from higher generic medicines utilisation among European countries. This exercise was carried out for illustrative purposes and does not claim to generate an exact estimate of savings from increased generic substitution. Generic medicines markets evolve rapidly so that, even though the most recent data relating to 2004 were used, the data may no longer reflect the market situation.

The policy and regulatory environment surrounding generic medicines influences the savings to be gained from generic substitution. For instance, a minimum price difference between originator and generic medicines has been imposed in several countries, amounting to 30 per cent in France and Spain, and 35 per cent in Portugal in 2004. This appears to be the main factor behind our estimated reduction in public expenditure on originator medicines of 35 per cent in France, 33 per cent in Spain and 42 per cent in Portugal as a result of increased generic substitution.

How can savings from increased generic substitution be attained? In countries with a high rate of generic medicines use, savings appear to have originated from the substantial price differential between generic and originator medicines, and increases in the consumption of generic medicines. ${ }^{2,8}$ This suggests that countries need to supplement supply-side policies, such as pricing reductions, by demand-side policies that create incentives for physicians, pharmacists and patients to use generic medicines. When developing generic medicines policies, issues relating to bio-equivalence between generic and originator medicines, quality assurance of generic medicines, and the impact of generic substitution on treatment compliance also need to be considered.

\section{CONCLUSION}

The G10 High Level Group on Innovation and Provision of Medicines in the European Union recommended in 2002 that member states promote generic penetration in domestic markets. ${ }^{9}$ Our findings suggest that the market share of generic medicines in several European countries is limited and that substantial savings could be gained from increased substitution of generic for originator medicines.

\section{Acknowledgments}

Financial support for this research project was received from the European Generic Medicines Association. Data were purchased by the European Generic Medicines Association from IMS Health. The authors are indebted to Ana Wisse Teixeira and Frank Bongers for their input into designing the study. The authors have no conflicts of interest that are relevant to the content of this short communication.

\section{References}

1. IMS Health (2004). Midas database. IMS Health, London, accessed February 2006.

2. Simoens, S. \& De Coster, S. (2006). Sustaining generic medicines markets in Europe. J. Generic Med. 3, 257-268.

3. Haas, J.S., Phillips, K.A., Gerstenberger, E.P. \& Seger, A.C. (2005). Potential savings from substituting generic drugs for brand-name drugs: medical expenditure panel survey, 1997-2000. Ann. Int. Med. 142, 891-897.

4. Cox, E., Behm, A., Mager, D. \& Miller, S. (2004). Generic drug usage report, Express Scripts, St. Louis. www.express-scripts.com, accessed 16th Jan 2006.

5. Tilson, L., Bennett, K. \& Barry, M. (2005). The potential impact of implementing a system of generic substitution on the community drug schemes in Ireland. Eur. J. Health Econ. 6, 267-273.

6. Fischer, M.A. \& Avorn, J. (2003). Economic consequences of underuse of generic drugs: evidence from Medicaid and implications for prescription drug benefit plans. Health Service Res. 38, 1051-1063.

7. Karim, S.S., Pillai, G., Ziqubu-Page, T.T., Cassimjee, M.H. \& Morar, M.S. (1996). Potential savings from generic prescribing and generic substitution in South Africa. Health Policy Plan. 11, 198-205.

8. King, D.R. \& Kanavos, P. (2002). Encouraging the use of generic medicines: implications for transition economies. Croatian Med. J. 43, 462-469.

9. G10 High Level Group on Innovation and Provision of Medicines in the European Union (2002). Recommendations for action, European Commission, London. http://europa.eu.int, accessed 14th March 2006. 